\title{
TRENDS OF VEGETATION FORMATION OF SOUTH-EASTERN AND NORTH-EASTERN OF PRE-BAIKAL (basin of Lake Baikal)
}

\author{
Victor Voronin $^{1}$, Alexander Sizykh ${ }^{1 *}$, Ruslan Moritz ${ }^{1}$ \\ ${ }^{1}$ Siberian Institute of Plant Physiology and Biochemistry SB RAS, \\ 664033, Irkutsk, Lermontova str., 132, Russia; \\ *Corresponding Author Alexander Sizykh, e-mail: alexander.sizykh@gmail.com;
}

Received September 2020; Accepted October 2020; Published November 2020;

DOI: https://doi.org/10.31407/ijees10.424

\begin{abstract}
In this paper there are new information about current structure and tendency of the vegetation formation for some areas of the Eastern Pre-Baikal. The aim of our studies is determining of maim peculiarities of structural and dynamical communities organization forming under the conditions of mutual development taiga and extrazonal steppe with identification of nowadays tendencies of plant communities genesis under the conditions of changing climatic situation and of dynamics of anthropogenic impacts as well. The vegetation cover in this case serves as an indicator for the changing natural situation in the Baikalian region at all.
\end{abstract}

Key words: trends of vegetation formation, taiga, extrazonal steppe, Eastern Pre-Baikal. 